\title{
Multimodal on Quiper Online Tutoring Adversisment
}

\author{
Nurhasanah Purba ${ }^{1}$, Agung Lasmono ${ }^{2}$, T. Thyrhaya Zein ${ }^{3}$ \\ 1,2,3Universitas Sumatera Utara, Indonesia \\ Email: Nurhasanapurba14@gmail.com,agungprrams@gmail.com, t.thyrhaya@usu.ac.id
}

\section{Abstract:}

This study aims to analyze the aspects contained in quipper online tutoring advertisements using multimodal analysis. This study uses qualitative methods to describe the object of research in accordance with what was observed and captured from the data obtained. In addition, the purpose of this method is to assist the research process by providing a more accurate picture. The multimodal concept used in this study is Cheong. The research results show that. There are 5 components in this advertisement, namely linguistic, visual, audio, spatial and genre, which in the linguistic analysis of speech used both oral and written verbal contain meanings that are easily understood by the public. In visual analysis, there are 5 visual stages that appear in this advertisement.

Keywords:

multimodal; advertisement; online tutoring

\section{Introduction}

Today many people rely on social media to develop products, both goods and services. Advertising is a means of developing a product, both goods and services effectively. Advertising is one way for a company to expose the advantages of their products to the general public. Advertising messages are also a means of conveying communication to inform or influence those who receive them. Therefore, advertisements are always present even though people may not notice it. Today, the use of advertisements for every medium makes it possible to convey the message. This is done through television, print (newspapers, magazines, journals and others), radio, press, internet, letters, contests, sponsorships, posters, clothing, events, colors, sound, visuals and even models in the endorsement.

According to Kasali (2007: 9) advertising is a message that offers a product that is addressed to the public through a media. Kotler and Keller (2007: 244) add that advertising is all forms of non-personal presentation and promotion of ideas, goods, or services by certain sponsors that must be paid. Based on the above understanding, it can be concluded that advertising is any non-personal presentation intended to promote ideas, or provide information about the advantages and benefits of a product that is financed by a certain sponsor.

Advertising is one form of communication consisting of information and ideas about a product that is aimed at the audience simultaneously in order to get a good reception. Advertising tries to provide information, persuade and convince. In other words, advertising is the most effective means of communication to disseminate information, product products, services and ideas from the advertiser, to the audience. (Suharyanto and Hidayat, 2018) 


\section{Linglit Journal: Scientific Journal of Linguistics and Literature \\ ISSN: 2774-4523 (Online), 2774-4515 (Print) \\ Vol. 2, No. 1, March 2021, Page: 9-16 \\ Email: linglitjournal@gmail.com}

Morissan in Hasnatang (2019), stated that the use of electronic media has various advantages compared to other media. It is not uncommon for advertisements to have an influence in shaping a person's lifestyle and tastes, which in this case is the impact of the symbols in the advertisement. Bourdieu (in Fashri, 2007: 142). The semiotics that exist in advertisements can be seen from the purpose of making advertisements which sometimes only think about profits without thinking about the negative impact of the advertising products offered

Relates to ad creation nowadays, advertisements regarding online learning methods are rampant, several online learning applications have become a trend due to the pademic situation. The concept of E-learning and Network-Based Learning is a form of learning model by utilizing application technology and the internet, the concept of learning and teaching is actually not a new thing, nor is it a new idea or thought, it has even developed since several decades ago. Various terms are used to express opinions / ideas about electronic learning, including: on-line learning, internet-enabled learning, virtual learning, or web-based learning based distance education, e-Learning, web based teaching and learning.

With the application of distance education based on applications and networks (internet, fax, fax-internet, etc.) then dependency the distance and time required for the implementation of education and training will be overcome, as all that is needed will be made available online so that it can be accessed at any time. This paper discusses matters relating to the application of internet and network technology as a form of learning method, by providing some information about the meaning, strengths, weaknesses, and some examples of methods related to this computer and network-based learning system.

One of them is Quiper. Quiper is an innovative product designed for distance learning. According to 2020 statistical data, 8,683 users use the Quiper application. The Quiper application is not only intended for students, but can be used for teachers. For Quiper students the online learning application makes learning more practical and easy to access via the internet. Learning can be anywhere and anytime. Not only learning by using text questions and theory. But the online learning app Quiper provides tutors with video teaching that can be repeated whenever they want.

Furthermore, in relation to appearance, an advertisement can be displayed explicitly or implicitly in a congruent or non-congruent manner. Multimodality is a term used to refer to the way people communicate using different modes at the same time (Kress and van Leeuwen, 1996), which can be defined as "the use of several semiotic modes in product design, or semiotic events simultaneously, and in certain ways. these modes are combined to reinforce, complement, or exist in a particular arrangement "(Kress and van Leeuwen, 2001).

Cheong (2004: 165) classifies components, guidelines (lead): attention reference (LoA) and complement to the reference attention (complement to the LoA) as being the core of advertising messages, presented in size and color with destingtive qualities compared to other visual components. Meanwhile, Camp. LoA has a function as a liaison and to focus audience attention on specific parts of the LoA.

Several authors have done multimodal research in advertisements, one of which is Rosa (2014) in her writing entitled Multimodal Analysis of Sunslik Nutrient Ginseng Shampoo Ads which uses the multimodal concept Cheong. This research reveals that these five multimodal systems are integrated in this advertisement. With regard to language metafunctions, in experiential functions, the use of material processes is very dominant $(83.33 \%)$. In the 
interpersonal function, all clauses use a declarative mood system (100\%). Whereas in the textual function, markless themes (TIM) dominate the types of themes used (66.67\%). In connection with the generic structure of the adddition element and the Number and Place order information are not found in the generic element of this ad.

This paper aims to read text on quiper online tutoring advertisements, which will then be used as a benchmark in assessing the actuality of existing social realities, which in the context of this paper is related to representations of Indonesian society that can be analyzed through multimodal texts.

\section{Review of Literatures}

\subsection{Advertising}

Kasali (2007: 9) defines advertising in a simple way, that advertising is a message that offers a product that is aimed at the public through a medium. Kotler and Keller (2007: 244) add that advertising is all forms of non-personal presentation and promotion of ideas, goods, or services by certain sponsors that must be paid. Based on the above understanding, it can be concluded that advertising is any non-personal presentation intended to promote ideas, or provide information about the advantages and benefits of a product that is financed by a certain sponsor. So many advertisements are in the midst of society, but experts try to classify them into several types of advertisements.

\subsection{Multimodal Analysis Model by Cheong (2004)}

Furthermore, Cheong (2004: 165-174) proposes a generic ad structure as shown in the following table:

Table 1. Generic Structure of Ads (adapted by Cheong, 2004: 165-174)

\begin{tabular}{ll}
\hline \multicolumn{2}{c}{ ADVERTISEMENT } \\
\hline \multicolumn{1}{c}{ Verbal Components } & \multicolumn{1}{c}{ Visual Components } \\
\hline \hline Announcement Primary, & Guidelines (Lead): Cautionary Reference \\
Second Announcement, & (Locus of Attention = LoA), \\
(Secondary Announcement) & Complement to \\
Enhancers & the Locus of Attention = Comp.LoA) \\
Verbal Emblem & Presentation (Display. Explicit, Implicit) \\
Message (Tag) & Congruent, Incongruent metaphorical \\
Contact Information (Call-and-visit & Visual Emblem \\
information) & \\
\hline
\end{tabular}

The table above shows the generic structure of the advertisement in terms of the verbal component and the visual component. This study discusses the verbal component and the visual component in the advertisement. Cheong (2004: 165) classifies components, guidelines (lead): attention reference (LoA) and complement to the reference attention (complement to the LoA) as being the core of advertising messages, presented in size and color with destingtive qualities compared to other visual components. Meanwhile, Camp. LoA has a function as a liaison and to focus audience attention on specific parts of the LoA. 
The visual component of presentation (display) serves to describe the product in a real and explicit manner. The visual symbol component (visual emblem) is visually realized through the advertised product logo which is linguistically manifest through the brand name or trademark, the symbol function provides identity or status for products that have a position on whichever side adjusts the proportion of the ad text (Sinar, 2018: 57 -58).

Then following the analysis (Cheong, 2004: 173), the linguistic elements that reveal and provide the essence of the meaning of an advertising message in an advertising text are Announcements (announcements), Enhancers (additions), Emblems (verbal symbols), Taq (messages), and Call and-visit information (contact information).

\section{Research Methods}

This study uses qualitative methods to describe the object of research in accordance with what was observed and captured from the data obtained. In addition, the purpose of this method is to assist the research process by providing a more accurate picture. The multimodal concept used in this study is Cheong (2004: 165-174) proposes a generic structure of advertising in the verbal component and the visual component. This study discusses the verbal component and the visual component in advertising. The data source used in this research is the online quiper learning video advertisement, which is broadcast on YouTubehttps://youtu.be/YYJ77W3UI7E on 17 November 2020. The data obtained in the form of the video will be converted into a piece of each scene in the form of a photo and then described in text form. After the data has been collected, the data obtained will then be analyzed using the multimodal concept according to Cheong.

\section{Results and Discussion}

The multimodal discussion of quipper online tutoring advertisements in this study uses the Cheong concept (2004). The analysis is as follows:

\subsection{Lingustic Analysis}

This Indomie ad played by Maudy Ayunda uses a combination of spoken and written language. The oral speech in the quiper advertisement is spoken by the ad star Maudy Ayunda, a beautiful young artist who is famous for her disbelief in the world of education, this beautiful girl has successfully passed scholarships at 2 well-known universities in the world, she is using a gown and medal and gives easy tips to face the UN. The chosen cast indicates that the online quiper tutoring is very good and is even recommended by young teenagers who are famous for their intelligence, here is the text used in this ad:

Teacher : Density, it's all about love, do you understand?

Students 2 : Understand sir

Boy student : Again please

Girl student : Biology,

Boy student 1 : Just physics,

Boy student 2 : Just economics

Boy student 1 : Math 
Maudy : Tips facing UN

Boy student : This is just fun

Maudy : On the quipper video you can learn to your heart's content, complete training questions, videos the tutorial can be repeated, the material can be downloaded

Students 2 : Come on, quipperan

Teacher : : Study again and pay only once

Maudy : Unlimited video Quipper, one-time pay

The verbal above is the formal variety that is usually used to invite or suit the community. This variety is used to encourage consumers to use products between messages and witnesses (consumers) as well as to show the modernity of this advertisement. Furthermore, the emphasis of the meaning contained in the verbal variety of the advertisement is strengthened and emphasized by the presence of written forms which are manifested in the form of visual emblems which are realized through product emblems.

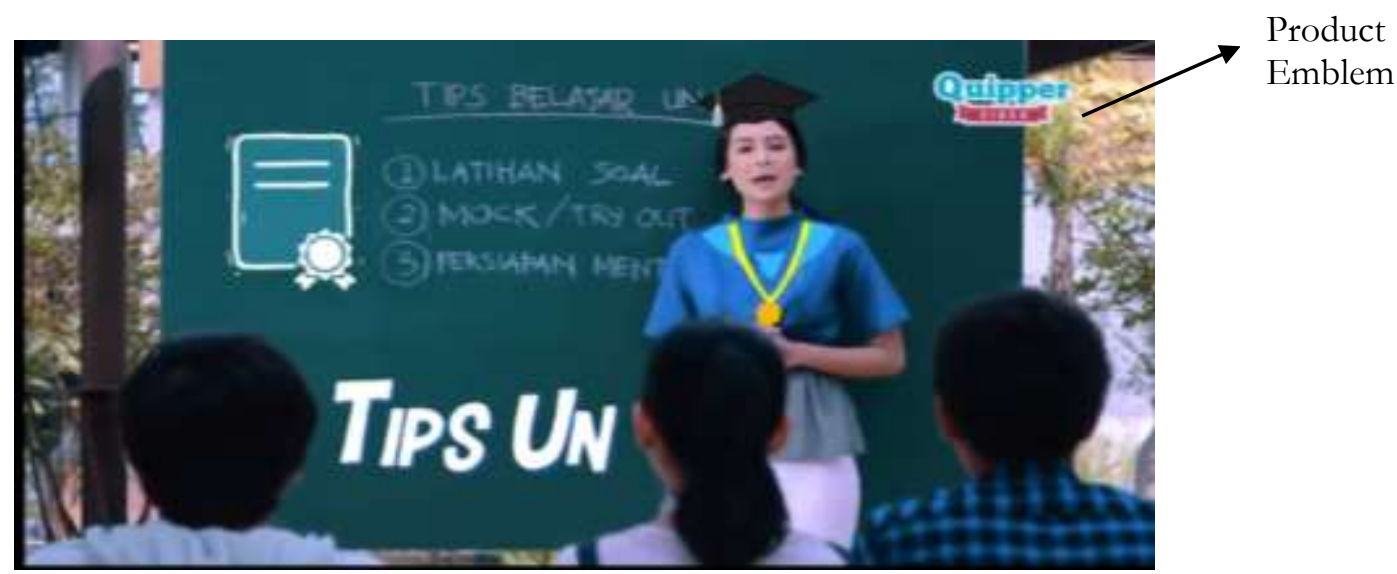

The message in the Quipper advertisement above is delivered in the form of an announcement which explains that the announcement is the only advertising message, the most important interpersonal aspect among other messages in the text, and the catch phrase aspect. The process that occurs on the announcement as the main message of the ad adThere is a material presentation in the form of video clips of learning, besides that there is an explanation of what the contents of this product are. Both the greeting and invitation processes have an imperative mode with commodity goods. This mode is a realization of an invitation to use an online tutoring product, namely quipper.

\subsection{Visual Analysis}

The appearance (visual) in the Indomie advertisement is realized in 5 visual stages, namely a) the visual of the commercial star shown by Maudy Ayunda, a beautiful and smart young artist. b) visual video quipper product about providing learning material, and c) Social and Equality showing the ease of using this product. d) visual setting shown by the learning video background which explains the advantages of the product offered. e). Visual Reactor which is shown by students around who are looking at the object that is the center of attention. These five visual displays last for 31 seconds. The realization of the five visuals is described in the following figure: 


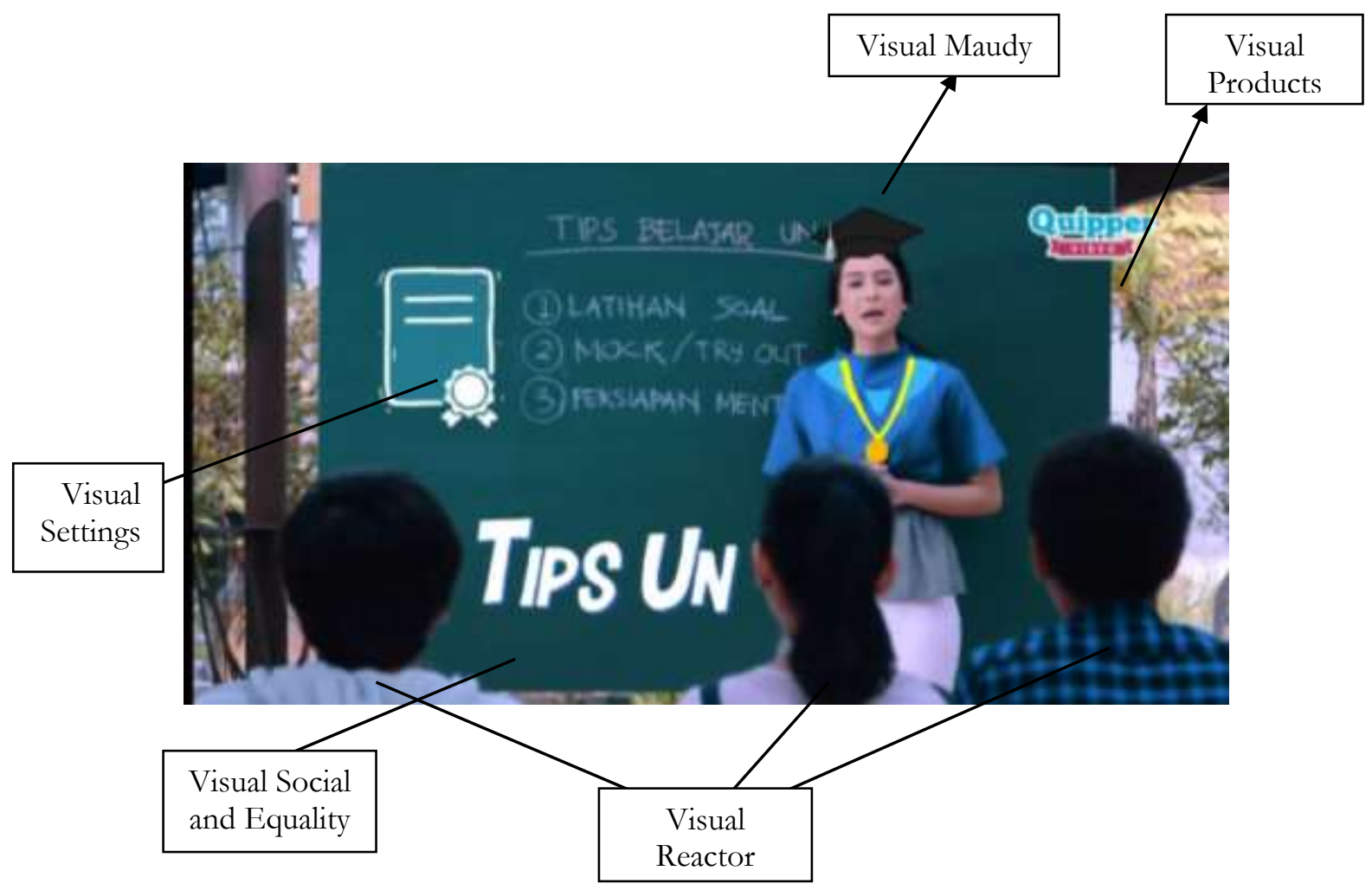

Furthermore, the combination of ad star visuals, product visuals, visual settings, Social and Equality visuals and visual reactors in quipper ads creates interpersonal meanings between participants and audiences. The interaction between commercials and students is manifested through eye contact and discussion which serves as tags. This situation indicates that the ad star is describing the item being offered. The next process is the interpretation of the goods offered by the advertisement star through spoken verbal text that explains the advantages of the product being offered.

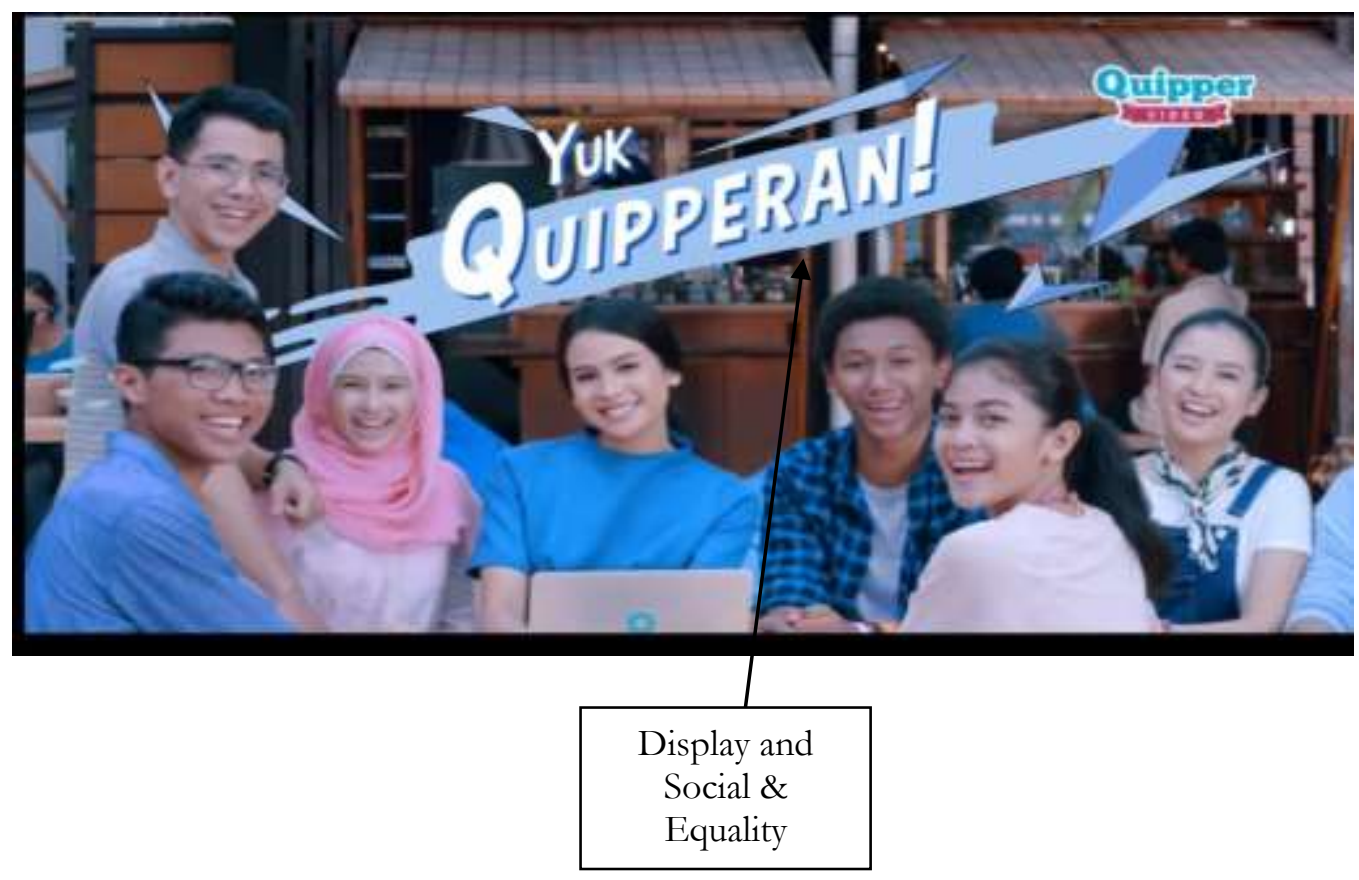


The taking of the viual elements in the text is to provide information to the public that the product is a product that can be owned and processed easily. Both of these are realized and can be found on Display and Social and Equality. This situation is very different in print advertising where social and equality is realized in cal and visit information.

\subsection{Audio Analysis}

The music that accompanies the activity in this advertisement is only instrumental music in the pop genre. The type of pop music used in this advertisement to show / or give the impression that this tutoring product can generate strong enthusiasm and is easy to access all lessons. This is getting stronger or is an affirmation of the superiority of the product is the use of oral verbal, "on the video quipper you can learn to your heart's content, the questions are complete, the video tutorials can be repeated, the material can be downloaded" the use of Silence is the delivery of product excellence to the audience on the visual activity of the participants.

\subsection{Spatial Analysis}

Overall, the distance between one image and another has shown the integration of the meaning of this advertisement. Each image does have its own meaning, but each meaning of the image supports the meaning of the other images. The depiction of the enthusiasm of participant activity, product excellence, and product convenience is shown by the distance between the image of an active advertising star and the material delivery process and how to use online quiper tutoring and the depiction of the Lead at the end of the advertising image marked with one finger and supported by verbal language. "Study again and again pay only once". This lead serves to give a deep impression and meaning to the user. The lead in this advertisement is a Locus of Attention (LoA) which is realized in the following image:

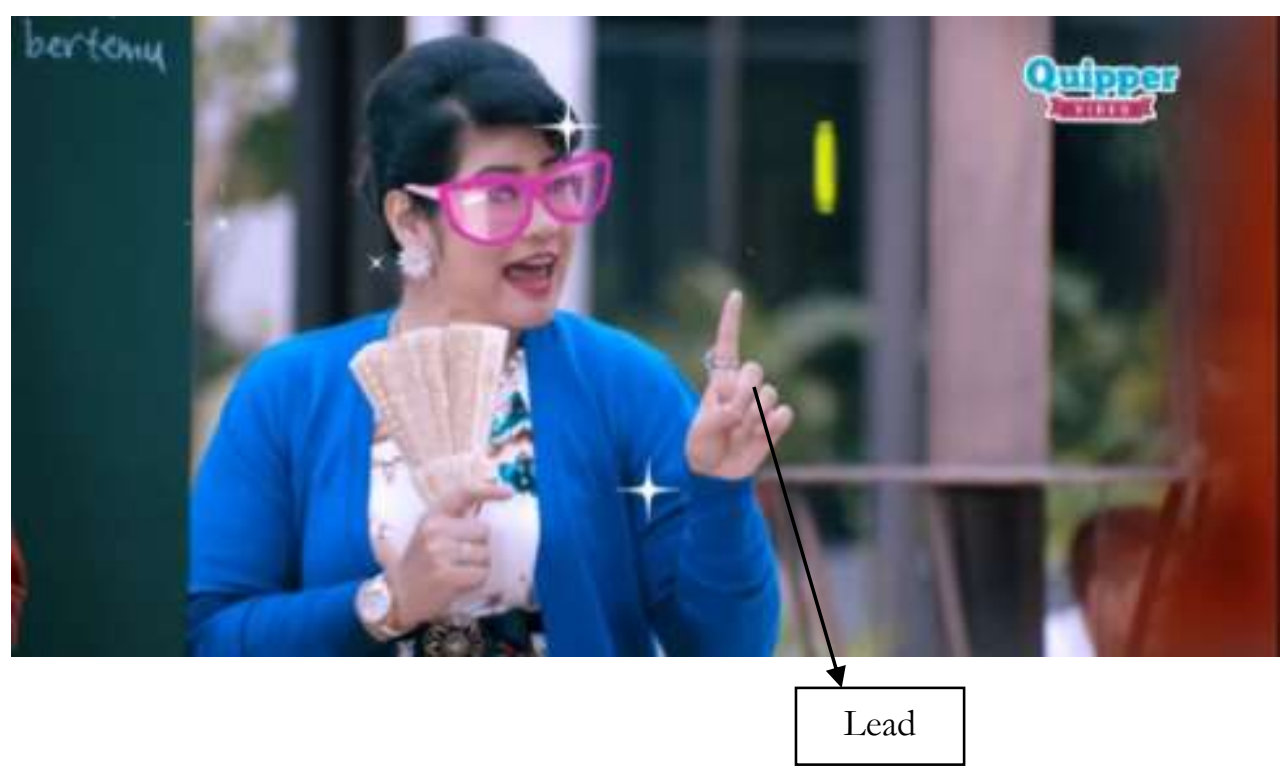

\subsection{Gesture Analysis}

Body speed and facial expression are gestures of commercial stars. Gestures in this advertisement are realized from the activities of commercials and students in using this online tutoring. This is reflected in the process of Actors and Goals as well as active and passive participants, where the participant's bid process occurs regarding the direct impact that can be obtained from consuming the products it offers. Active and passive participants in this advertisement are shown through verbal verbal from the active participant, "Quipper video for unlimited learning, one time payment" followed by written verbal from the product emblem. The process description is realized from the following figure. 


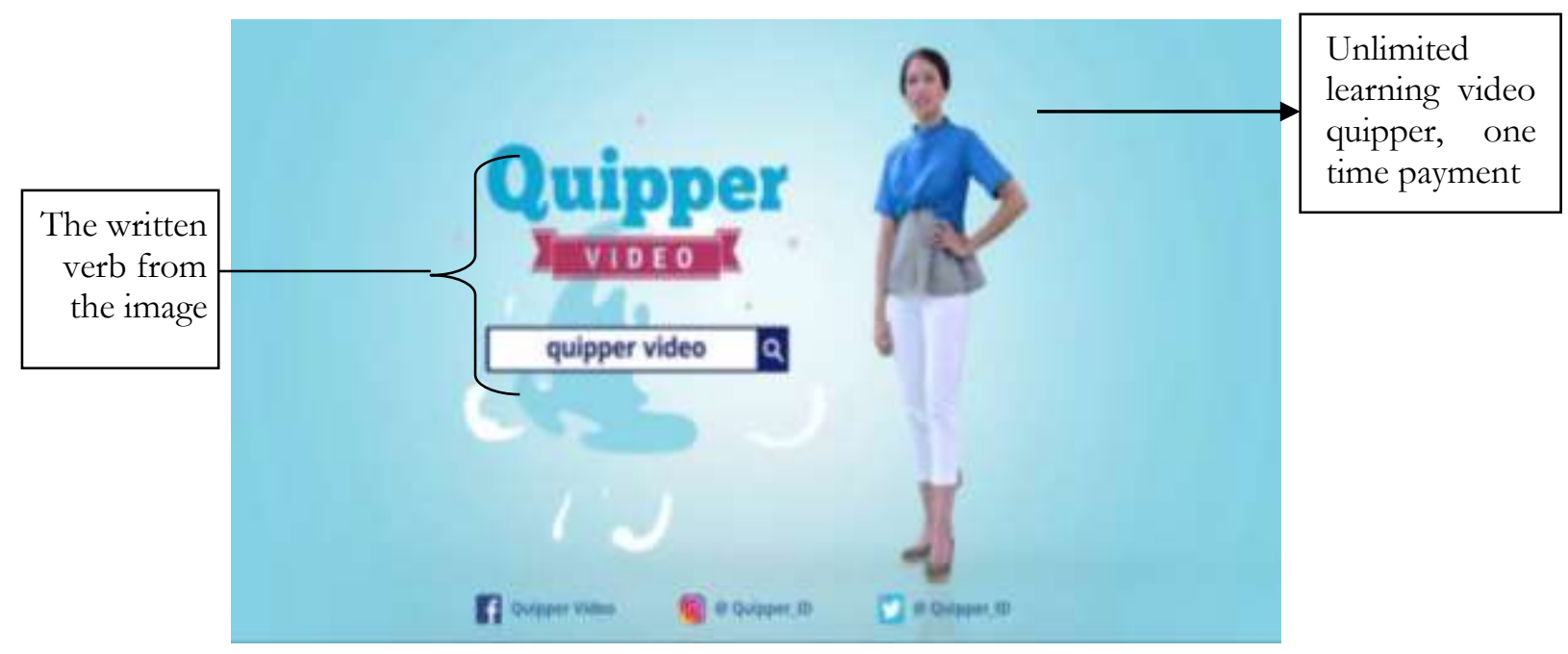

\section{Conclusion}

Based on the results of the multimodal analysis of the online tutoring advertisement, the conclusion is that there are 5 components in this advertisement, namely linguistic, visual, audio, spatial and genre, which in the linguistic analysis of speech used both verbal and written verbal contain meanings that are easily understood by Public. In visual analysis, there are 5 visual stages that appear in this advertisement, namely the visual ad star that has a background that is in accordance with the purpose of the ad, product visuals, social visuals and equality, visual settings, and visual reactors. The audio used is in accordance with the atmosphere that is raised, expressive gestures make this advertisement add to the interest of every student to use it.

\section{References}

Cheong, YY (2004). "The Construal of International Meaning in Print Advertisements". In Kay L. O'Halloran (Editor) Multimodal Discourse Analysis: Systemic-Functional Perspectives. London: Continuum. Thing. 163-195.

https://media.neliti.com/media/publications/78384-ID-none.pdf

https://media.neliti.com/media/publications/79553-ID-pembelajaran-berbasis-e-learning.pdf https://www.researchgate.net/publication/330906343_Design_Aplications_Media_Pembelajara

n_Untuk_Membantu_Pem]_Siswa_Tentang_Konsep_Geometri

Kasali, R. (2007). Advertising Management Concept and Its Application in Indonesia. Jakarta: Pustaka Utama Grafiti.

Kotler, P. and Keller, KL, Translator Benyamin Molan. (2007). Marketing Management. Twelfth Edition, Volume 1. Jakarta: PT. Index.

Kotler, P. and Armstrong, G. (2007). Principles of Marketing. Lodon: Pearson prentice Hall.

Kress, G and Theo. VL (2001). Multimodal Discourse The Modes and Media of Comtemporary Communication. Great Britian: Arnold.

Roda, R. (2014). Multimodal Analysis of Sunslik Nutrient Ginseng Shampoo Advertisement. Linguistic Studies, Year I2, No 2, August 2014

Sinar, TS (2018). Multimodal Discourse Analysis of Systemic Functional Linguistic Theory. Medan: USU Press. 